\title{
SHARED-REGULATION AND MOTIVATION OF COLLABORATING PEERS: A CASE ANALYSIS
}

\author{
Marja VAURAS'), Tuike IISKALA ${ }^{1)}$, Anu KAJAMIES ${ }^{1)}$, Riitta KINNUNEN ${ }^{1)}$ and Erno LEHTINEN ${ }^{1)}$ \\ 1) University of Turku, Finland
}

\begin{abstract}
Little attention has yet been focused on the social nature of metacognition and motivation in adult- or peer-mediated learning, although reciprocal or transactive interaction between individuals is emphasized as a road to learning, that is, in teaching and mediation of knowledge and skills. The present article presents a case analysis and focuses on (a) exploring if and how socially shared-regulation and (b) motivation and coping are manifested in high-ability, 4th grade students' peermediated learning in a technology-based game environment, specifically constructed to foster problem solving in mathematics. The case analysis supported the notion that peer-mediated learning can produce high-level learning and, also, transfer of learning. The key conditions for effective collaboration, task-orientation, and social and cognitive competencies, were met in the case of the peers. The analysis further suggested that the notion of shared-regulation could be helpful in understanding of multilevel interaction and regulatory activities in learning. The concept of sharedregulation best seemed to mirror egalitarian, complementary monitoring and regulation over the task, thus bringing the research closer to phenomena relevant to joint, peer-mediated learning. It seemed that regulation in true collaboration fluctuates among the three modes of regulation, self-, other-, and shared-regulation. We concluded, however, that collaborating peers do not regularly meet these ideal conditions, and that the more complete picture of joint problem solving and regulation is complex and variable. Understanding of these multilevel regulatory activities in learning, and their relationship to other, multilevel concepts like motivation, social competence, context, and learning, is a challenge for future research.
\end{abstract}

Key words: shared-regulation, motivation, peer-mediated learning, elementary school, high-ability, word problems, learning game, technology-based learning

The literature on motivation and metacognition is still strongly focused on individuals' behavior and learning. Thus the prefix self is often added to concepts that mirror these key phenomena like self-regulation. Although the learning and volitional processes are, predominantly, described at individual level, reciprocal or transactive interaction between individuals is emphasized as a road to learning, that is, in teaching and mediation of knowledge and skills. This emphasis is generally clear in current notions on learning stemming from cognitive-constructivist theories, and it is the explicit basis of socio-constructivist views. Little attention has yet been focused on the social nature of

This research was supported by Grant No. 47369 from the Council for Cultural and Social Science Research, The Academy of Finland, to the first author. We wish to thank the participating schools, teachers and students, who unfortunately must remain anonymous.

Correspondence concerning this article should be addressed to Marja Vauras, Department of Teacher Education, University of Turku, FIN-20014 Turku, Finland (E-mail: Marja.Vauras@utu.fi). 
metacognition and motivation in adult- or peer-mediated learning. The notion of shared cognition has been introduced (e.g., Salomon, 1993), but, we can ask, whether such terms as shared-regulation, or even shared metacognition, would highlight the control or executive processes (e.g., Perkins, 1993) involved in transactive peer learning. Although these concepts have not been used, recent research, e.g., on collaboration or peer tutoring, have stressed the mutual mediation processes in learning and problem-solving situations. Terms like negotiation, argumentation, collaborative inquiry, supportive communication, and shared meanings and interpretations reflect these social processes (e.g., Dillenbourg, 1999; King, 1998; Perkins, 1993).

One major interest in our recent project, Quest of Meaning, is transactive and collaborative learning and, particularly, the social nature of metacognition and motivation in young, elementary school learners. The present article focuses on exploring if and how shared-regulation is manifested in high-ability, 4th grade students' collaboration in a technology-based game environment, and if the notion of shared metacognition might be warranted. We are also interested in how motivation and coping behavior are manifested in peer-mediated learning. Here, we present a case analysis of two high-ability students (who worked as a pair for eight weeks in a game environment). The learning environment, Quest of a Silver Owl (QSO), was specifically constructed to foster problem solving in mathematics ${ }^{1}$. In contrast to peer tutoring models (see e.g., King, 1998), students worked together without systematic tools for training peers to discuss and to collaborate. However, the actual game was designed in a way that was hoped to optimize students' motivation and collaboration.

\section{Transactive Peer-Mediated Learning}

Rooted in Vygotskian ideas (e.g., Vygotsky, 1978), current socio-cognitive theories of learning emphasize the social mediation of knowledge and skills by more capable others. Through guided participation (Rogoff, 1990) or scaffolding (Wood, Bruner, \& Ross, 1976), the learner gradually internalizes or "appropriates" (e.g., Rogoff, 1990) knowledge and skills, and, thus, along with increased mastery, other-regulation progressively transfers to self-regulation. In mediation processes, thinking is actually seen as actually being distributed between the one who is guiding the participation and the one who is appropriating knowledge, meanings and skills (King, 1998). This distributed thinking has been labeled cognitive partnership (Perkins, 1993). The cognitive partnership is often described between unequal participants, e.g., between parent and child, or teacher and student. However, in contemporary research, more attention has also been shifted to egalitarian cognitive partnerships between peers. King (1998, p. 59) describes this peer partnership as mutual appropriation in the following way:

\footnotetext{
${ }^{1}$ The project Quest of Meaning is primarily focused on students with learning difficulties in reading comprehension and mathematics. The analyses of high-skilled students' collaboration and metacognitive regulation, besides being of theoretical interest, also serve as a frame for analyzing poor students' interaction and for elaborating the scaffolding procedures of special teachers. Our core interest areas of teacher scaffolding also include the mediation and transfer of executive function to students in the learning process, and helping students to build collaboration skills.
} 
"Because both partners have some expertise that they mutually appropriate, and they share the cognitive demands of the learning task, there is reciprocity in their interaction and activity. Further, when one partner responds to each other, that response is dependent on the other partner's question or comment; and is often framed by that question or comment. At the same time, that response may prompt to a great extent the next question or comment made. A partner's comments, questions, and responses are not only dependent on those of the other partner, they are also dependent on the learning task at hand ... and the learners' developing understanding ... When there is such reciprocity and interdependence in the transactions between learning partners, and between those partners and the task, the process of thinking and learning can be said to be "transactive" in nature." (p. 59)

Egalitarian cognitive partnerships or peer-mediated learning are explicated in the contemporary literature on collaboration and peer tutoring. Dillenbourg (1999) names a situation collaborative if the peers (i) are at roughly the same level and can perform the same actions, (ii) have a common goal, and (iii) work together. A certain degree of symmetry in action, knowledge, and status is thus expected. On top of these situational characteristics, the first criterion for collaborative situations is interactivity. However, the interaction is not defined quantitatively, e.g., as a frequency of interactions, but "by the extent to which these interactions influence the peers' cognitive processes" (Dillenbourg, 1999, p. 12). Hence, collaboration requires more than the effective division of labor that constitutes cooperative work (Littleton \& Häkkinen, 1999).

Two crucial courses of action feature these collaborative interactions: synchronicity and negotiation. As Roschelle and Teasley (1995) have defined it, collaboration is a coordinated, synchronous effort to construct and maintain a shared conception of a problem. Synchronous communication can be seen as a well-disposed metacommunicative contract, that is, the partners try to maintain subjective feeling of synchronicity of reasoning. In face-to-face interaction, this synchronicity of reasoning often leads partners to make the same utterance simultaneously or to complete utterances. (Cf. Dillenbourg, 1999.) Recently, the need for reciprocal understanding between collaborators has been highlighted as an essential prerequisite for collaborative learning (Littleton \& Häkkinen, 1999). Such reciprocity involves partners establishing mutually shared knowledge through negotiation. In addition to negotiating at the task level, collaborative partners usually have the possibility to negotiate how to interact (metacommunication). However, negotiation occurs only if there is space for it. Negotiation can be hindered in many ways, such as too well defined roles, trivial tasks etc. (see Dillenbourg, 1999).

According to Dillenbourg (1999) the grounding process is the bottom layer of the negotiation. Grounding is seen as a process by which partners augment and maintain a common ground of mutual understanding, knowledge, beliefs, assumptions etc., also during the interaction itself (Baker, Hansen, Joiner, \& Traum, 1999). Very similarly, Teasley and Roschelle (1993) have argued that collaborative problem solving enables the construction of shared conceptual structure. They call it a joint problem space (JPS). A JPS integrates semantic interpretations of goals, features, methods, and so on. Students use the structure of conversation to continually build, monitor and repair a JPS. The turntaking structure of "collaborative completion", in which one partner begins an idea and the other one uses the next turn to complete it, characterizes the process of joint problem 
solving. The dyads also have a tendency to maintain a shared conception of the problems by consenting understanding in communication. Teasley and Roschelle importantly noted that language is not the only tool, but that the use of action, movement or gesture is material. Thus, they focused more attention also on non-verbal communication during collaboration.

All these notions imply that transactive cognitive partnerships require sophisticated social and communication skills, such as inter-subjectivity and the abilities to understand the partner's point of view, to communicate one's own views, to communicate unambiguously, to listen actively, to plan ahead, and to inhibit one's own actions (see Ding \& Flynn, 2000). Furthermore, learners are rarely experts in a process of learning, that is, in how. Peer-mediated learning presupposes not only mutual appropriation of knowledge and meaning, but also mutual scaffolding and guidance (King, 1998). Educational intervention research (e.g., Pressley, 1995) shows how expertise in scaffolding is long-term pursuit even for professional teachers. We cannot expect that young students acquire the complex skills involved in collaboration and mutual scaffolding without any help and guidance.

It is also naïve to believe that effectual peer-mediated learning in classrooms frequently take place (see e.g., Cohen, 1994). In typical classroom learning, there is, still today, little space for genuine collaboration and peer-mediated learning. The core of collaboration, the executive function, is often ceded to the setting, often to the teacher, and the educational setting typically maintains extensive executive control through the formal learning process despite the learners' increased mastery of the knowledge and skills (Perkins, 1993). The learners are occasionally left to work alone or in groups or dyads, unprepared, however, to take responsibility for the executive function, and the processes needed in effectual collaboration. Hence, we can argue that when egalitarian peers are involved, learning activities tend to be restricted to cooperation and lower-level learning: mutual checking of task elements, memory or comprehension checking, and rehearsal of facts and concepts (cf. King, 1998). Since transactive learning is seen as a powerful road to high-level learning, great efforts are made to find instructional designs that promote both unequal and egalitarian cognitive partnerships. Therefore, different person-plus (Perkins, 1993) cognitive partnerships — including person plus technology — have been constructed and studied in order to enhance peer-mediated activities, such as collaborative inquiry, negotiation, and joint meaning construction that support high-level learning (see, e.g., Dillenbourg, 1999; King, 1998; O’Donnell \& King, 1999).

\section{Motivation and Cognitive Partnership}

From the motivational point of view, the traditional way of organizing and conceptualizing teaching-learning processes as sequences of distinct acts is very clear. Certain episodes are deliberately intended for motivational interpretations. Different motivation theories focus on the different phases of this activity sequence. For example, interest and goal orientation as well as self-efficacy and expectancy value theories, describe students' interpretations of the tasks, while attribution and self-worth theories focus on the interpretation of the feedback. The traditional teaching-learning process 
makes success and failures obvious, and highlights comparison and achievement among students. (Vauras, Salonen, Lehtinen, \& Lepola, 2001). In traditional teaching-learning contexts, the distinct, individual level concepts have been valid and eligible for describing human motivation. However, when we move to instructional designs that are based on the cognitive partnership model, in-person concepts alone become problematic.

In new learning environments, the roles of the players in the educational game are no longer so clear. For example, it is not possible to find a clear teacher role as a task giver or evaluator or clear start- and end-points of teaching-learning events, and it is difficult to find explicit information for making causal attributions. In ideal collaborative contexts, the diverse strengths of students are valued and cultivated, and joint efforts and "products" emphasized in place of individual contribution. It is possible that competition and ability comparison can not be avoided even in the best designed collaborative environments, but certainly the explicit information about individual abilities and achievement levels becomes even more invisible (Vauras et al., 2001).

Attractive assumptions concerning the motivational effects of new learning environments have been made. For example, transferring more responsibility to students may increase students' autonomy and sense of personal control, which in turn, facilitates intrinsic motivation and task commitment (Turner, 1995). Peer models may provide benchmarks for students' own self-evaluations, helping them to set more accurate goals, and to gain confidence in their own ability to succeed (e.g., Bandura, 1997; Järvelä \& Niemivirta, 2001). Despite these attractive motivational assumptions, very little is yet really known about volitional processes and motivational effects of transactive peermediated learning. However, some general-level positive motivational effects, along with progress in knowledge and skills, have been reported (e.g., Bruer, 1993, Lamon, Secules, Petrosino, Hackett, Bransford, \& Goldman, 1996) and, also, more specific analyses are emerging (e.g., Järvelä, Lehtinen, \& Salonen, 2000; Rahikainen, Järvelä, \& Salovaara, 2000). However, there are two sides of the coin, and we can expect that the motivational effects of peer collaboration may also have serious drawbacks in some cases. Without adequate support from setting, a simple beneficial motivation hypothesis is unwarranted, especially in the case of low-ability students. We have earlier referred to the heavy demands of collaboration or peer-mediated learning on students' cognitive and social competency. The notion of collaboration itself presupposes task-orientation, persistence and some degree of intrinsic motivation, and, therefore, we also have to explore more carefully the volitional processes, which are prerequisites for true cognitive partnerships.

We are at liberty to assume that in order to explicate motivation in collaborative settings, especially between egalitarian peers, we need inter-person concepts also in the models of motivation. Undoubtedly, there is a need to deal with motivation not only as a separate variable but also as an inherent part of a socially and culturally embedded activity (Vauras et al., 2001; for extended discussions on motivation in context, see Volet \& Järvelä, 2001). 


\section{Peer Collaboration in the Quest of the Silver OWL (QSO)}

\section{A Case Analysis of High-Achieving Girls}

The mathematics instructional game, Quest of the Silver Owl (QSO) (Vauras \& Kinnunen, 2001) was "played" by eight 4th grade high-achieving and eight 4th grade lowachieving students (four girls and four boys in both groups) for eight weeks, for approximately 30-45 minutes at a time, twice a week. Students worked as same-ability pairs, and, altogether, there were 16 sessions per pair. The game goals could be achieved by solving mathematical word problems and calculation tasks. The word problems reflected the spirit of the game, and a variety of one- to multi-step problems was used, from simple, e.g., compare and combine, addition and subtraction tasks to more complicated multiplication, division and mixed tasks with, e.g., equal measures, rate, area, conversion, and Cartesian product problem situations. A parallel series of pre-, post- and follow-up-tests (different types of word problems and arithmetic tasks) was administered, and the students were also tested in these skills six times before (prior-to-game baseline tests) the game sessions began, eight times during (during-the-game tests), and six times after (post-game tests) the sessions. All baseline tests were as comparable as possible, and included eight arithmetic tasks (e.g., 213+9-13, 17×9), and two multi-step word problems of two difficulty levels. Easier problems included approximately 40 words and numbers, and required measure transformation and calculations, e.g., 72/6=12 deciliters, or $305 \times 5=1525 \mathrm{~mm}$. More complex problems included approximately $95-105$ words and numbers, and required calculations, e.g., $16+6=22,16+22=38,38 \times 3=114,114-12=102$, or $52-16=36,52+36=88,88 / 8=11$.

There were some implicit sets of executive decisions built into the game (cf. Perkins, 1993). These included turn-taking, that is, shifts between player and evaluator roles, demands on writing the solution in a specific form on the screen (expression(s), solution, unit), instructions to check the solution, and evaluation if the solution is correct. The game structure and goals, freedom of choice in task difficulty, free pacing, multiple feedback on progress and an attractive graphic environment were designed as the main motivational incentives. With the low-achieving students, the teacher provided active scaffolding, but with the high-achievers, the teacher remained more invisible. In this way, the high-ability students' opportunity to regulate their activities at the metacognitive level was enhanced. In teacher-student interaction, the teacher has a tendency to control interaction (cf. Kumpulainen \& Wray, 2002). Thus, in the QSO game, the actual problemsolving phase gave the high-ability peers freedom to establish their own ways of working together and to build and monitor their joint problem space.

All game sessions were videotaped. The high-achieving pairs were videotaped by applying a mixer, which allowed a simultaneous picture of the computer screen and the up-from-waist picture of the players. After-the-problem and stimulated recall interviews were used with high-achieving students. During the sessions, the teacher (the second author of this article) interviewed the pair immediately after one of the word problems before the pair got the feedback on their solution. At the end of the sessions, the stimulated recall interview was conducted. The main questions focused on the solution 


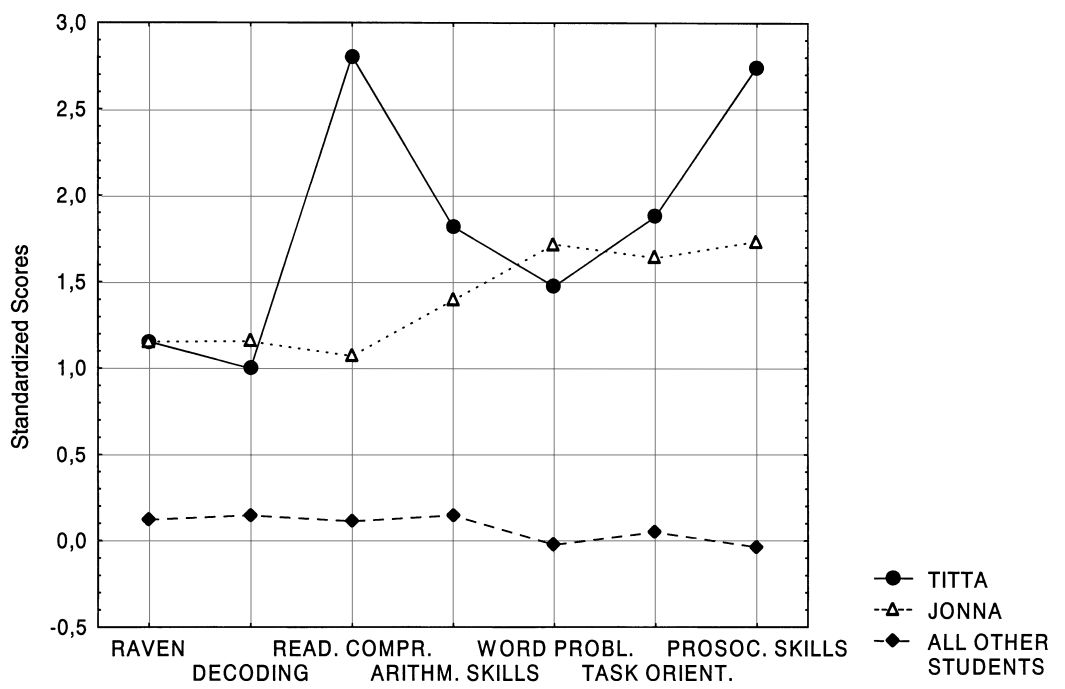

Fig. 1. Titta's and Jonna's performance (standardized scores) on various screening tests compared to all other mainstream students $(n=395)$.

processes (“Tell me, how you...?", "Did you both think in a similar way?", "Assess, how you succeeded"), and on discussions and collaboration ("Did you understand what your pair meant?", "How was your collaboration?", "What were the benefits or problems in collaboration?"). The interviewer always asked the students to explain and to give reasons as precisely as possible.

For the present analysis, we chose one top-achieving girl pair (called here TITTA and JONNA). Titta was 10 years and 8 months and Jonna 10 years and 3 months old when the baseline tests began. The girls attended a city school of good reputation and high standards. However, the school could be described as traditional in terms of learning environment. Hence, the girls had no extensive experience of collaboration from their classroom studies. On most screening tests (including e.g., Raven progressive matrices, decoding, reading comprehension, arithmetic skills, and word problems), these girls ranked among the upper $2-15 \%$ of all the 4 th grade mainstream students $(n=395)$ participating in the Quest of Meaning project (see Fig. 1.) Their teachers assessed these girls as highly task-oriented, and both teachers and classmates judged that their social competency (prosocial skills) was high. (See Fig. 1.) We assumed that this girl pair would best model non-trained, spontaneous collaboration of young, 4th grade students. In Fig. 2, Titta's and Jonna's (independent) performance on baseline tests is presented. This figure indicates a generally high level performance, but also some instability in the performance. The behavior seemed to fluctuate somewhat, as a function of situational factors like mood or physical condition.

In the pre-, post- and follow-up-tests (the number of word problems in each test was 15), the girls' performance was high already prior to the game. In these three tests, Titta's scores (percentage correct) were 76.7\%, 97.7\% and 98.8\%, and Jonna's $80.2 \%, 88.4 \%$ and 


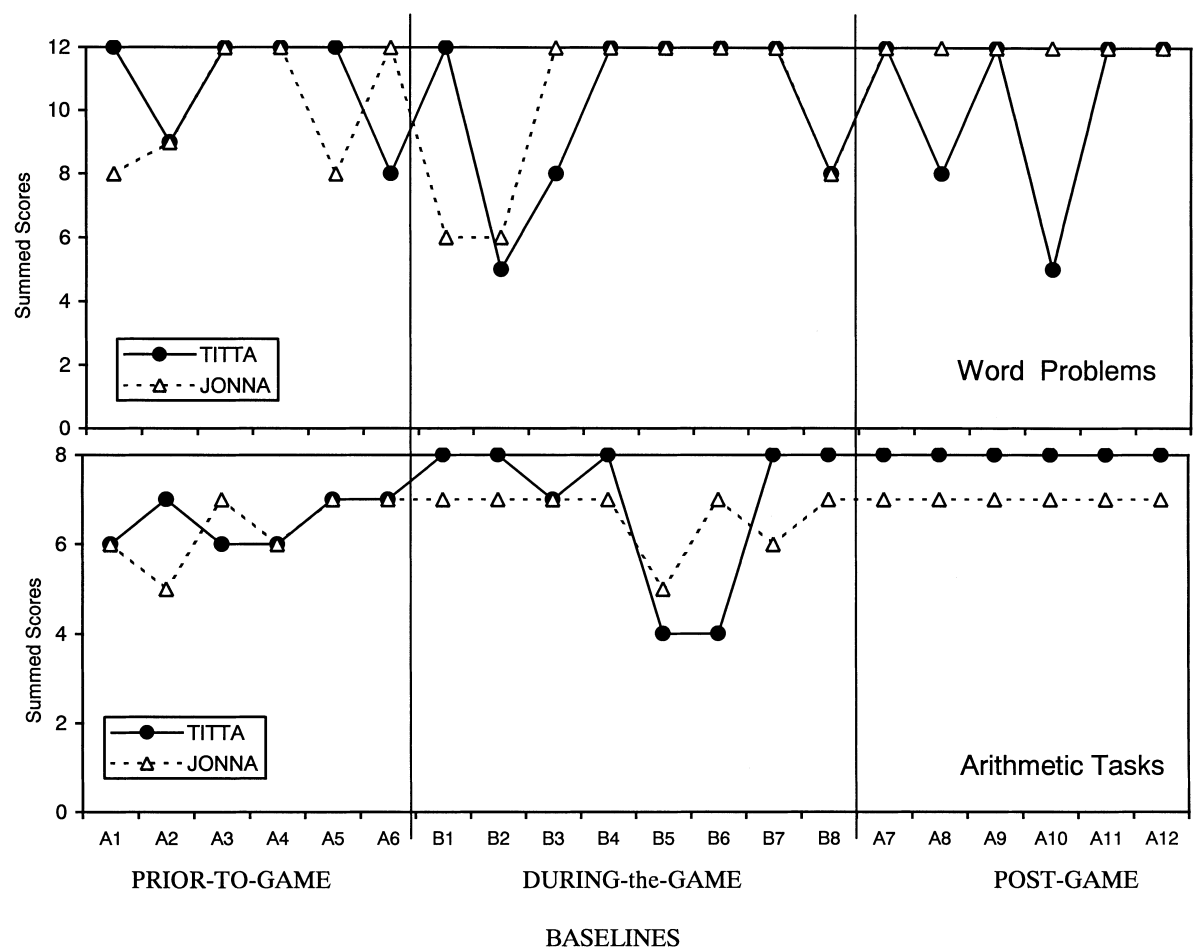

Fig. 2. Titta's and Jonna's performance on baseline tests prior, during and after the game sessions. Note. One measure point in the upper panel always consisted of two (simple and complex) word problems $(\max =12)$, and one measure point in the lower panel consisted of six arithmetic tasks $(\max =8)$.

$96.5 \%$, respectively. The scores are based on qualitative analysis in which we took into account the number of correct steps and the answer. In pre-tests, Cartesian product, problematic word problems, and some rate and measure conversion problems were difficult for both girls. In the two first mentioned problem types, they did not construct a correct situation model, whereas in the latter ones, calculations were to some extent erroneous. In post- and follow-up-tests, these problem types created no difficulties, and the main errors were made in counting with large numbers. This is an interesting learning result in the light of collaboration during the game sessions.

For this girl pair, the second author of this article carefully transcribed each word spoken during the sessions, including the stimulated recall interviews. Non-verbal communication, like pointing and eye contacts were written down. The time on task was measured, and the use of extraneous tools described.

\section{The Content and Quality of Collaboration}

Task Choices and Time on Task. Whenever possible, Titta and Jonna always unanimously selected word problems that offered them some challenge. The first two task levels (Border Land and Mist Land problems) were of no challenge to them, and as soon 
Table 1. Number of Correct and Incorrect Solutions in Problems Chosen by Titta and Jonna, and Mean Times on Problem

\begin{tabular}{|c|c|c|c|c|c|}
\hline Problem difficulty: & $\begin{array}{c}\text { Level } 1 \\
\text { Border Land }\end{array}$ & $\begin{array}{l}\text { Level } 2 \\
\text { Mist Land }\end{array}$ & $\begin{array}{c}\text { Level } 3 \\
\text { Rain Land }\end{array}$ & $\begin{array}{l}\text { Level } 4 \\
\text { Fire Land }\end{array}$ & $\begin{array}{c}\text { Level } 5 \\
\text { Magic Land }\end{array}$ \\
\hline Correct solutions & 15 & none selected & $17^{\mathrm{a}}$ & 22 & 12 \\
\hline Incorrect solutions & 0 & - & 2 & 4 & 2 \\
\hline \multicolumn{6}{|l|}{ Mean time on task: } \\
\hline Correct solutions & $1 \mathrm{~min} 10 \mathrm{sec}$ & - & $1 \mathrm{~min} 17 \mathrm{sec}$ & $5 \mathrm{~min} 01 \mathrm{sec}$ & $6 \mathrm{~min} 00 \mathrm{sec}$ \\
\hline Incorrect solutions & - & & $2 \mathrm{~min} 24 \mathrm{sec}$ & $4 \mathrm{~min} 07 \mathrm{sec}$ & $13 \mathrm{~min} 02 \mathrm{sec}$ \\
\hline $\begin{array}{l}\text { Mean time on correcting } \\
\text { the incorrect solution }^{\mathrm{b}}\end{array}$ & - & - & $7 \mathrm{~min} 36 \mathrm{sec}$ & $3 \mathrm{~min} 17 \mathrm{sec}$ & $4 \mathrm{~min} 00 \mathrm{sec}$ \\
\hline
\end{tabular}

${ }^{\text {a }}$ Titta and Jonna selected these tasks primarily because Level 4 problems were finished at the time, and they could not yet select Level 5 problems. ${ }^{\mathrm{b}}$ The girls corrected all incorrect solutions.

as possible, the girls began to select the fourth (Fire Land) and fifth level (Magic Land) problems, which were more suitable for their competence level. However, they were not particularly frustrated when, at one point, they had to resort to the third level (Rain Land) problems for a while. Table 1 gives an overview of the girls' problem choices, time ontask and competency to solve problems together. The table reveals important features of the girls' collaboration and motivation. They adequately regulated their time on task according to problem difficulty. Their task-orientation and persistence are shown by the facts that they always spontaneously wanted to reach the correct solution and spent the necessary time on repairing their understanding when correcting the solutions if errors occurred.

Creating a Common Ground and Regulating Activities during the First Sessions. During the first two sessions, when the girls could not yet choose the difficulty level, the word problems were very easy for them, and offered no possibility of higher-level learning. This was shown in their zero error rate and short time on task (see Table 1). However, right from the start, Titta and Jonna showed self-regulated activity (like stopping in order to think in face of uncertainty, checking their understanding and calculations). In addition to self-regulation, they also engaged in reciprocal regulation, and gave signals to the partner, if they were not ready to move on or to accept the solution. Throughout the collaboration, their typical discussions included utterances like "Hey, wait a minute ...", "No, but look. It is ...", "I have to check ...", "Isn't it like ..., and "How so?" They also wanted to check if the other agreed and was ready to move on, e.g., "What shall we put here?", "Shall we write ... ?" They readily took part in assisting each other to clarify and to comprehend the problem or to repair calculation procedures. Thus, they seemed to realize from the start that the partner would not simply consent to the other's solution, however competent it appeared to be. Both needed the feeling of certainty and insight, and the partner appreciated this. An example (2nd session) illustrates self- 
regulation and assisting:

JONNA: But isn't it like 13 plus 15 ? (looking at Titta)

TITTA: Hmmm, I got quite off the track ...

JONNA (rephrasing part of the problem): That how many snakes there had been under the bridge before the elf game there.

TITTA: So?

JONNA: That is, isn't it like 13 plus 15 ?

TITTA: Perhaps, but I'd still like to look.

From the following comments, it became obvious that Titta had not constructed the situation model correctly (and offered 15-13). Jonna corrects her idea by explicitly focusing Titta's attention to crucial points of the text.

JONNA: But look there, it says lifts, the elf lifts 13 black snakes into his basket, and while he peeks under the bridge again, he counts that there are still 15 fat snakes ... so, isn't it 13 plus 15 ?

Titta now agrees and writes the solution on the screen.

TITTA: I still have to check here.

It soon became obvious that Titta was about to make errors of haste in some easy tasks, perhaps due to their apparent easiness. Jonna adopted the friendly monitoring role, and stopped Titta form accepting erroneous solutions. Typically, she focused Titta's attention more closely to crucial elements of the problem. Both girls were very open in their communication. For example, Titta always recognized her own haste without any defenses, like in the example from the 3rd session: After Jonna had explained how she understood the problem, Titta says "Yeah, now I ..." (corrects her solution confidently and writes 17+4=21) ... "I didn't read it carefully enough".

Appreciation of Different Strategies. After the girls could choose problems from three difficulty levels (Mist Land, Rain Land or Fire Land task), they began to monitor and regulate their problem solving behavior even more carefully. They also realized that they used different counting strategies. Titta, predominantly, wanted to make calculations in her head (irrespective of steps demanded or the size of the number) and to write complex statements using parentheses, whereas Jonna more readily used paper-and-pencil to employ algorithms and settled for separate, sequential statements. Often, they also counted in different order. Their appreciation of these differences became clear in the stimulated recall interviews, as short extracts (from 3rd and 4th sessions) witnessed.

JONNA: That was quite a difficult task in itself.

TITTA: We both had exactly the same idea, but ...

JONNA: But somewhat different statements.

TITTA: And a bit different in details, but surely we both would have reached the same answer.

TEACHER: Did you each understand what the other meant?

TITTA: Yes.

JONNA: I didn't at first understand what Titta meant but then gradually I figured it out.

TEACHER: When did you understand what Titta meant?

JONNA: Then, when Titta explained here, what she was doing there (points to Titta's notebook, and explains in detail, how Titta had solved the problem).

TEACHER: Did you count in a similar or a different way?

JONNA: Well, we had the same terminal point, but we didn't use same calculations. 
The girls became very conscious of their different strategies, and the negotiation on the selection of the strategy became a regular part of their collaboration. If asked, they were able to explain each other's way of thinking and solving the problem.

Appreciation of the Benefits of Collaboration. The girls understanding of the benefits of collaboration became more explicit in the course of the game. They emphasized how 'thinking together' and 'telling aloud' built better understanding, how the other's different approach or solution attempts inhibited her own course of action and gave a reason to stop and think more carefully, and how they could learn new things together. They also expressed pleasure in their joint pursuit, and they came to appreciate their own as well as their partner's abilities. Three examples below illustrate this growing appreciation of collaboration.

TITTA (2nd session): Well, when we were thinking, that shall we take my solution ... or we were thinking together, and then when we both agreed, we didn't have disagreements ...

JONNA: That you could always do better and better, you came along with each other, that if we always work here together ...

TEACHER (3rd session): You mentioned that two heads are better than one. What do you mean by it? TITTA: When we are two, we can do better ... Two are together.

JONNA: Like, if in some task, both see it differently, or it is a rather difficult ... task, then like both tell how they're thinking ... then I begin to wonder how to decide which one is right ...

TEACHER: Did you have some problems in your collaboration today?

JONNA: Perhaps on two (occasions) when the other tried to explain the task.

TITTA: We had in quite many, but in my mind I had it wrong, but then you said your own option and then we did as Jonna said.

TEACHER: So then, what about this collaboration, what benefits did it have, altogether?

TITTA: They (tasks) were easier ...

JONNA: Yes, and then, these were a bit more difficult tasks, and then like, you learned somehow new things like that...

TEACHER (6th session): Now that you did this together, did you learn something about each other?

TITTA: Yes, that we are pretty clever (the girls chuckle).

TEACHER: And what else?

TITTA: That we are doing quite well in our collaboration.

JONNA: And, we have to look carefully at the calculations.

TEACHER: How did you recognize that your collaboration went well?

TITTA: Because, when one noticed something, the other began to think ... we told the other ... told aloud ... and she noticed that the other one is of a different opinion, then we pondered is it now quite like this or like that ... and then we figured it out ...

Collaboration in Difficult or Unfamiliar Problems, and Learning from Collaboration. Although many task types were not familiar to the girls from classroom work, they solved the problems rather smoothly through mutual negotiation. There were three types of problems, which created dilemmas: Area, Cartesian product (see Greer, 1992) and problematic word problems (see Verschaffel, De Corte, \& Lasure, 1994). In all except in one problematic word problem (see below), Titta and Jonna reasoned the right solution through mutual negotiation (using variably tools like drawing and counting on their notebooks, or asking hints from the computer). We give three (shortened) examples of their discussions during these problems. 
Problematic problem (Fire Land) (5th session): You help the fisherman of Lake Flame to put the boulter in water between the quay and Blaze Island. The distance between the quay and the island is 77 meters. The fisherman has only eleven-meter long lines in his shed. How many lines do you need to pull the boulter from the quay to Blaze Lake?

JONNA: $77 / 11$, or ...

TITTA: No, wait a bit, I didn't get it right yet, what, hmmm ... (thinking)

Rather quickly $(1 \mathrm{~min} 20 \mathrm{sec}$ ) the girls decide that $77 / 11=7$ is a correct answer. They receive feedback incorrect. They chuckle, and look at each other.

JONNA: These are pretty difficult.

TITTA: This is wrong ... (somewhat later) But I put 11 times 7, so let's look what it is.

After a while they begin to count in the notebooks.

TITTA: But now we would divide them by pieces 11 meters' long (looking at Jonna)

JONNA: To my mind the (earlier solution) was quite correct.

Both read the problem silently.

TITTA: Now I am going to make a drawing.

After some comments, Titta turned to the teacher.

TITTA: We can't figure it out.

Teacher scaffolds by giving at first subtle hints (girls mutter hmm ... after each hint), but finally she gives a direct prompt.

TEACHER: If you put them one after the other, and then pull, they are not connected to each other. (Teacher shows with her hands.)

TITTA: Hmm ...

JONNA: Do we need one more then? (The girls look at the teacher.)

TITTA: Maybe we need eight then (looks at the teacher and Jonna).

TEACHER: And why would you need eight?

TITTA: Well, to attach them together.

TEACHER: How do you attach them?

TITTA: With a knot.

TEACHER: Yes and these knots would take some of the measure.

Now the girls understand the problem, and know the answer. They still have difficulties in marking the correct statement. At one point Titta proposes $(77+1) / 11$, but abandons it quickly as impossible. Finally they agree and write $(77 / 11)+1=8$ on the screen. They spent altogether $12 \mathrm{~min} 8 \mathrm{sec}$ on the problem.

During the next (6th) session, the girls encountered a similar problem and recognized the problem-type immediately.

TITTA: Hmmm (thinking), we need eight ... no, nine.

JONNA: This is now like that, that you need one more there.

The girls write $(32 / 4)+1=9$. However, Jonna is not quite sure, and wants to check the solution by counting it in her notebook. It took $2 \mathrm{~min} 15 \mathrm{sec}$ to solve the problem and to check it.

Area problem (Rain Land)(8th session): The rain wizard gave engineer Drizzle an important task. The king wanted to see his beloved dolphins every day, and Drizzle had to plan a big swimming pool for them on the courtyard. Drizzle scrutinized and measured the courtyard. He was quietly muttering to himself: "Here is good, soft soils to dig. Between the stone passages is left a good 13 meters. What about the pool length? It is exactly 24 meters from the flowerbed to the castle's outer wall. I leave one meter at each side of the pool for fine sand passages. So, let's make the pool 11 meters wide and 22 meters long. How big does the pool's area become like this?"

TITTA: We surely haven't had this kind of task yet.

JONNA: Hmm, hmm ... (thinking), if, like, you have there now, you have square shaped that thing.

TITTA: I'll look (takes her notebook). 
JONNA: And look, then it makes like 2 times 13 and 2 times 24 .

TITTA: Wait.

JONNA: And then you summarize them.

The girls looked intently at the task on the screen.

JONNA: Or would it be 2 times 11 and 2 times 22 ?

TITTA: But here is, like, measure of a square meter, and because ... because that comes, like, 22 times 11 (looks at the teacher and Jonna).

JONNA: You don't need square meters, here it says only meters.

TITTA: But, but when of area ...

JONNA: But this is the whole thing.

TITTA: Yeah, but we can't measure what is like those ...

JONNA: Yes we can, what this edge ... or what the length of the edge is, and then it comes from it (the girls look at each other, then at the teacher).

TITTA: But look, since 11 and 22, that is, like that 11 times 22, that like ...

JONNA: Then it becomes the whole area (Jonna draws a square shaped area in the air with her hands, and looks at Titta).

TITTA: Yes ...

JONNA: That is the area.

TITTA: Yes, that is what the pool will become and that how much... mustn't it be done like square and meters (chuckles), well, when we haven't had these yet (looks at the teacher).

Jonna writes on the screen $2 \times 11$.

TITTA: Wait, it isn't like that (erases the statement).

JONNA: Yes it is like that 2 times 11 plus 2 times 22.

Titta now writes $2 \times(22+11)=66$ on the screen.

JONNA: 66 meters.

TITTA: This is wrong, surely, but let's do it anyway ...

(They spent $3 \mathrm{~min} 35 \mathrm{sec}$ on the problem, gave their answer, and got the feedback from the computer: The solution is incorrect.)

It was obvious that the girls already possessed core concepts related to area problems. However, these concepts were still isolated, and were not structured as a representation of an area problem. This is probably the reason why Titta, although she proposed the right solution quite early, was not herself sure of it and could not explain this solution to Jonna. After the first solution attempt, the girls began to construct a more coherent problem representation, and step by step Titta's explanations and Jonna's reactions to them become more accurate. Titta herself also became more confident in her thinking.

TITTA: Hey, what did I say (erases all numbers). Because that is like 22 meters times 11.

JONNA: No but, it surely has to be 2 times 13 and 2 times 24 .

TITTA: No ... o, because then you measure only how much the edges are.

JONNA: Yes, and then from it, remains the room there inside ...

TITTA: But if we think, you see (takes her notebook).

Jonna is not yet ready to abandon her idea that the correct solution must be $2 \times 13$ plus $2 \times 24$ or $2 \times 11$ plus $2 \times 22$. During their conversation, Titta continues to draw on her notebook, and at one point she raises her head.

TITTA: But it is asked there this pool area ... Here is now the pool ... two, four, six, eight, ten, but here is this pool, and this is 11 and this 22 meters, and this is one meter ... as a matter of fact, like, this is like one meter multiplied by one meter (explains from her notebook drawing).

JONNA: Yes, one meter multiplied by one meter is like a square meter, and it says nothing here about square meters.

TITTA: The same. 
JONNA: But let's try this $(2 \times 11$ plus $2 \times 22=66)$.

TITTA: Well, let's look.

(They spent $3 \mathrm{~min} 35 \mathrm{sec}$ on correcting, gave their answer, and got the feedback from the computer:

The solution is incorrect).

JONNA: But if it is like $2 \times 13 \ldots$

TITTA: But you are counting how long those edges are, you are not counting the content, it asks here for the area (shows her drawing again).

JONNA: Should it ... 11 times 22 times 2.

TITTA: Hmm (thinking) I don't now quite ...

JONNA: OK, lets count, one, two, three, four, yes it is 11 times 22 , then you count how many meters there are inside (counts from Titta's notebook).

TITTA: But look (signals that she wants to begin to write on the screen). Jonna erases everything and Titta writes $11 \times 22=$.

TITTA: Wait, I have to count it here (takes her notebook).

JONNA: 66.

TITTA: No, it is 44.

JONNA: I got 253 ... but you have to count here, look, you have to put zero there ...

After some counting, Titta reaches the solution and writes $11 \times 22=242$.

TITTA: Is this now meters?

JONNA: 242 meters, square meters.

(Now they spent 2 min $14 \mathrm{sec}$ on correcting, gave their answer, and got the feedback from the computer: The solution is correct).

After the solution, Titta still wants to know how to mark a square meter.

JONNA: Don't you usually say like $m$ two (looks at the teacher, who confirms and asks).

TEACHER: Do you know why we wrote there square meters?

TITTA: Because it is the area.

Later, they solved more difficult area problems. At the 5th level (Magic Land) the area problems demanded separation of a smaller area from a bigger one, as in the example below.

Area problem (Magic Land) (11th session): Magic Land's architect Secretpen planned a garden corner for the prince's dog. The dog became uneasy in the little tower, where the prince lived. The prince thought that it would be good for the dog to get out whenever it wanted to. The tower's backyard was nine meters long and 14 meters wide. Secretpen separated an area by the tower for the dog. This area was four meters long and seven meters wide. How many square meters were left for other use?

JONNA: Hey, this is again like this, 9 times 14 , because here is now ... Hey, wait, here ...

TITTA: How did we solve this the other time?

JONNA: When you put it ...

TITTA: There must ...

JONNA: It is that square meters.

TITTA: But I don't remember how I did it.

JONNA: How much of the backyard is left for other use?

Very quickly both remember the right procedure, and write $9 \times 14-4 \times 7=98$ square meters.

It now took $2 \mathrm{~min}$ and $24 \mathrm{sec}$ to reach the correct solution and to check the problem. In the 13th session, they got a similar task with very large numbers like 20000 square meters. They had no problems in constructing the situation model or in remembering how this type of problem must be solved. Most of the time they spent counting large numbers to get the right answer. It took 6 min $45 \mathrm{sec}$ to complete the task. It was obvious that they had learned to solve area problems from the first problem (on 8th session) which they 
painstakingly solved together, and they readily applied the correct procedures to more difficult ones.

The third difficult problem type was Cartesian product. When they encountered this type of problem for the first time, they jumped quickly to the "obvious" incorrect solution. After the first hasty attempt, the girls realized that the problem posed a true challenge for them, and used a long time to construct a situation model. In this task, the collaborative completion (Teasley \& Roschelle, 1993) was very visible.

Cartesian product (Rain Land) (9th session): Only experienced boatmen can row on the Lake Beaver, because it is full of beaver nests. You look amazed at the map of Lake Beaver. It is marked how six safe routes leave from the Ferry Bank to Middle Island. From there are only two safe routes to Beaver Fall, and from there you get four routes to the shore of Beaver Lake school. By how many different routes can the ferrymen transport pupils from the Ferry Bank to the school?

TITTA: Hmm, like 6 plus 2 plus 4 (writes $6+2+4=12$ on the screen). Well?

JONNA: Yes, it is ...

(They spend only $1 \mathrm{~min} 22 \mathrm{sec}$ on the problem, give their answer, and get the feedback from the computer: The solution is incorrect.)

JONNA: Luckily, I said that it doesn't matter if it goes wrong.

The girls read the problem again silently. After some comments:

JONNA: I don't even understand that problem.

The girls start to discuss the problem, and ask if they can write other than numbers on the screen. They begin to write 'to one island', 'are only 2 routes, and from the third are 4 routes ...' After this, they continue to discuss.

TITTA: When there are six routes to one island and from the other ...

JONNA: and the other ...

TITTA: and from the other island there are only two routes and from the third one four routes, so you can travel only by two routes.

The girls begin to draw in their notebooks, and rather soon they realize that they can choose different routes. However, they conclude that their solution, two routes, is correct.

(They spend $6 \mathrm{~min} 43 \mathrm{sec}$ on correcting, give their answer, and get the feedback from the computer: The solution is incorrect.)

TITTA: What did I say, what did I say ... (erases the solution) We have to multiply here.

JONNA: I don't get it, wait ...

Both take their notebooks and begin to count.

TITTA: There is one island (shows her drawing), one island, one island and the end point island. From here go six routes, and from this two routes, and hey, that is 6 times 2 times 4, perhaps (looks at Jonna and the teacher, and Jonna continues to count on her own notebook).

Titta writes on the screen $6 \times 2 \times 4=$.

TITTA: Perhaps it is like this, twelve.

JONNA: 48 (Titta nods approvingly, and filling the result 48).

(They spend $1 \mathrm{~min} 23 \mathrm{sec}$ on correcting, give their answer, and get the feedback from the computer: The solution is correct.)

In the stimulated recall interview, the girls comment on their process a bit annoyed.

TITTA: Well, here we count it wrong ... we don't think, and we simply begin to count and then we count it incorrectly.

JONNA: One could say that you count incorrectly, because $I$ don't understand a bit of it!

After the second failure, Titta comments.

TITTA: There I got some kind of a great brainwave ... although it went wrong again ...

Titta becomes quite irritated at her own behavior when watching the following events.

TITTA: Here comes the stupid point, when I start to write ... it is stupid, because I begin to write and I do not think that we have done everything wrong.

Some events later: 
TITTA: Soon we see the point, where I start to blabber with that notebook, and first then I realized that it was incorrect.

TEACHER: Why is it an important point?

JONNA: Because she understood it.

TITTA: Yeah, then I realized that what I have been actually thinking ... you sure can take all the routes. JONNA: At that point, I didn't quite yet understand it well.

Later in the tape, Titta shows and explains her drawing to Jonna.

JONNA: Well, here Titta shows those routes, and I then I realized ... like you can take different routes, and then I ...

TEACHER: How did you realize?

JONNA: When Titta had made the drawing and explained ... that when Titta had drawn the picture and explained it in that way.

Finally, they watch how Titta is mumbling about islands and the end point.

TITTA: Well, here I became conscious that one has to multiply.

During the next (9th) session they encountered two similar Cartesian product problems. They solved these without any difficulty, and spent only $58 \mathrm{sec}$ and $35 \mathrm{sec}$ on the tasks.

\section{DISCUSSION}

It is argued that collaborative or peer-mediated learning produces high-level learning (cf. e.g., King, 1998). This case analysis supported this argument. The learning from collaboration and the transfer of learning were rather striking in the case of the two highability girls, Titta and Jonna. This was evident already during the game sessions, manifesting in one-shot learning and immediate transfer to more complex problems. The learning was also supported by post- and follow-up test performances, where e.g., Cartesian product and problematic word problems were solved without difficulty. Over seven months later (at follow-up) Jonna evaluated her solution on the Cartesian product task: "The task was easy to understand, because we have solved similar problems with Titta in the math club". In many problems, the girls referred to their learning in the "math club", that is, during the QSO-game. Our analysis seemed to indicate that, in future research, more attention must be paid to how the overall structure and content of peer discourse and collaboration are related to learning (cf. Chinn, O’Donnell, \& Jinks, 2000).

However, it is obvious that effective collaboration requires sophisticated social and communication skills (Ding \& Flynn, 2000) as, in this case were visible. One very distinct feature of successful collaboration seems to be openness, that is, non-defensive ways of reacting to one's own actions (e.g., haste), misinterpretations, or comprehension failures and to the partner's helping reactions and guidance. The partner has to be ready to "confess" and communicate her own lack of comprehension, to ask for help if needed, to give help in a friendly but adept manner, to be ready to listen and to take into account the partner's opinions, and to resolve disagreements without a sense of personal threat. This non-defensiveness opens the space for mutual problem solving and shared-regulation.

The interrelationships between shared-regulation and motivation clearly pose a challenge for research, because of their complex and reciprocal nature. Shared-regulation, 
negotiation and high-level problem construction itself presuppose keen concentration on the task, that is, task- or problem-orientation. The girls in this study, Titta and Jonna, showed undisturbed task-orientation throughout all sessions. This even intensified in challenging, unfamiliar or difficult, tasks. Although top-achieving students are typically highly task-oriented, irrespective of the nature of the learning environment (e.g., Lehtinen, Vauras, Salonen, Olkinuora, \& Kinnunen, 1995), we may hypothesize that the game setting and the free space for joint problem solving increased intrinsic motivation and ontask behavior (cf. e.g., Turner, 1995). Nonetheless, the key conditions for effective collaboration, task-orientation, and social and cognitive competencies were met in the case of these two girls. On the other hand, we can assume that high task-orientation is augmented and maintained by shared regulation processes. Skilful regulation of the aspiration level hinders boring the participants with too easy tasks and frustrating them with too difficult ones. Mutual helping in a meaningful way aids the peer who is momentarily at a loss to overcome frustration and to keep up the task-oriented behavior, and, thus, persistent efforts are continued despite comprehension problems.

But do we need to talk of shared-regulation in addition to self-regulation or otherregulation? High awareness and regulation of own thinking (self-regulation) seems to be the bottom line in the girls' working throughout the sessions (as evidenced, e.g., in comments like 'I got quite off the track', 'I'd still like to look', 'Wait a bit, I didn't get it right yet, what ...', 'I don't even understand that problem'). However, when we scrutinize the discourse extracts, it is difficult to interpret the overall regulation of the reciprocal problem solving evident in them by using only the concepts of self- or other-regulation. The subtle collaborative completion (Teasley \& Roschelle, 1993) included constant monitoring and regulation of joint activity, which cannot be reduced to mere individual activity. At times, when one partner masters a key element of the task but the other does not, a momentary unequal situation arises. In these situations, regulation is best described as other-regulation (see e.g., the area problem, where Titta gradually became sure of her own solution, and guided Jonna to realize how she is not counting the area inside the edges, p. 31). In most such cases here, the situation soon became balanced, and the pair resumed joint, coequal discourse to complete their understanding and to solve the problem. During this kind of discourse, the concept of shared-regulation best seems to mirror this egalitarian, complementary monitoring and regulation over the task, thus bringing the research closer to phenomena relevant to joint, peer-mediated learning. It seems that regulation in true collaboration fluctuates among the three modes of regulation, self-, other-, and shared-regulation. It also appeared to be the case that the nature of shared-regulation depends on the complexity of the task or the problem in hand.

Here, we have illustrated spontaneous, peer-mediated learning and shared-regulation through high-ability students' collaboration in a non-guided, technology-based environment. This gives us only a brief glimpse of the issue in a rather ideal situation. We can safely assume that these ideal conditions are not regularly met by collaborating peers, and that the more complete picture of young students' joint problem solving and regulation is complex and variable. However, we have very little understanding of these multilevel regulatory activities in learning, and their relationship to other, multilevel concepts like 
motivation, social competence, context, and learning. We also lack knowledge of how teachers can effectively mediate executive control (cf. Perkins, 1993) to help less competent peers to gain shared metacognitive competence.

\section{REFERENCES}

Baker, M., Hansen, T., Joiner, R., \& Traum, D. 1999. The role of grounding in collaborative learning tasks. In P. Dillenbourg (Ed.), Collaborative learning. Cognitive and computational approaches (pp. 3-63). Advances in learning and instruction series. Amsterdam: Pergamon.

Bandura, A. 1997. Self-efficacy: The exercise of control. New York: Freeman.

Bruer, J. T. 1993. Schools for thought. A science of learning in the classroom. Cambridge, MA: MIT Press.

Chinn, C., O'Donnell, A., \& Jinks, T. 2000. The structure of discourse in collaborative learning. Journal of Experimental Education, 69, 77-97.

Cohen, E. 1994. Restructuring the classroom: Conditions for productive small groups. Review of Educational Research, 64, 1-35.

Dillenbourg, P. 1999. Introduction: What do you mean by "collaborative learning?" In P. Dillenbourg (Ed.), Collaborative learning. Cognitive and computational approaches (pp. 1-19). Advances in learning and instruction series. Amsterdam: Pergamon.

Ding, S., \& Flynn, E. 2000. Collaborative learning: An underlying skills approach. In R. Joiner, K. Littleton, D. Faulkner, \& D. Miell (Eds.), Rethinking collaborative learning. London: Free Association Books.

Greer, B. 1992. Multiplication and division as models of situations. In D. Growns (Ed.), Handbook of research on mathematics teaching and learning (pp. 276-295). Macmillan: New York.

Järvela, S, Lehtinen, \& Salonen, P. 2000. Socio-emotional orientation as a mediating variable in teaching learning interaction: implications for instructional design. Scandinavian Journal of Educational Research, 44, 293-307.

Järvelä, S., \& Niemivirta, M. 2001. Motivation in context: Challenges and possibilities in studying the role of motivation in new pedagogical cultures. In S. Volet \& S. Järvelä (Eds.), Motivation in learning contexts. Theoretical advances and methodological implications (pp. 105-127). Advances in learning and instruction series. Amsterdam: Pergamon.

King, A. 1998. Transactive peer tutoring: Distributing cognition and metacognition. Educational Psychology Review, 10, 57-74.

Kumpulainen, K., \& Wray, D. 2002. Classroom interaction and social learning. London: RoutledgeFalmer. Lamon, M., Secules, T., Petrosino, A., Hackett, R., Bransford, J., \& Goldman, S. 1996. Schools for thought: Overview of the international project and lessons learned from one of the sites. In L. Schauble, \& R. Glaser (Eds.), Innovations in learning. New environments for education (pp. 243-288). Mahwah, NJ: Erlbaum.

Lehtinen, E., Vauras, M., Salonen, P., Olkinuora, E., \& Kinnunen, R. 1995. Long-term development of learning activity: Motivational, cognitive, and social interaction. Educational Psychologist, 30, 21-35.

Littleton, K., \& Häkkinen, P. 1999. Learning together: Understanding the processes of computer-based collaborative learning. In P. Dillenbourg (Ed.), Collaborative learning. Cognitive and computational approaches (pp. 20-30). Advances in learning and instruction series. Amsterdam: Pergamon.

O’Donnell, A., \& King, A. 1999. (Eds.). Cognitive perspectives on peer learning. Mahwah, NJ: Erlbaum.

Perkins, D. 1993. Person-plus: A distributed view of thinking and learning. In G. Salomon (Ed.), Distributed cognitions: psychological and educational considerations (pp. 88-110). Cambridge: Cambridge University Press.

Pressley, M. 1995. A transactional strategies instruction Christmas carol. In A. McKeough, J. Lupart, \& A. Marini (Eds.), Teaching for transfer. Fostering generalization in learning (pp. 177-213). Mahwah, NJ: Erlbaum.

Rahikainen, M., Järvelä, S., \& Salovaara, H. 2000. Motivational processes in CSILE-based learning. In Proceedings of the International Conference for Learning Sciences (June, 2000). Mahwah, NJ: Erlbaum.

Roschelle, J., \& Teasley, S. 1995. The construction of shared knowledge in collaborative problem solving. 
In C. O’Malley (Ed.), Computer-supported collaborative learning (pp. 69-197). Berlin: SpringerVerlag.

Rogoff, B. 1990. Apprenticeships in thinking: Cognitive development in social context. New York: Oxford University Press.

Salomon, G. 1993. (Ed.). Distributed cognitions. Psychological and educational considerations. Cambridge, MA: Cambridge University Press.

Teasley, S., \& Roschelle, J. 1993. Constructing a joint problem space: The computer as a tool for sharing knowledge. In S. Lajoie, \& S. Derry (Eds.) Computers as cognitive tools (pp. 229-257). Hillsdale, NJ: Erlbaum.

Turner, J. 1995. The influence on classroom contexts on young children's motivation for literacy. Reading Research Quarterly, 30, 410-441.

Vauras, M., \& Kinnunen, R. 2001. HoPE - Hopeisen Pöllön Etsintä. Opetuspeli laskutaitojen ja matematiikan ongelmanratkaisun taitojen kehittämiseen [Quest of the Silver Owl, Educational computer game for improving arithmetic and mathematical problem solving skills]. University of Turku, Centre for Learning Research, Finland.

Vauras, M., Salonen, P., Lehtinen, E., \& Lepola, J. 2001. Long-term development of motivation and cognition in family and school contexts. In S. Volet, \& S. Järvelä (Eds.), Motivation in learning contexts. Theoretical advances and methodological implications (pp. 295-315). Advances in learning and instruction series. Amsterdam: Pergamon.

Verschaffel, L., De Corte, E., \& Lasure, S. 1994. Realistic considerations in mathematical modeling of school arithmetic word problems. Learning and Instruction, 4, 273-294.

Volet, S., \& Järvelä. S. 2001. (Eds.). Motivation in learning contexts. Theoretical advances and methodological implications. Advances in learning and instruction series. Amsterdam: Pergamon.

Vygotsky 1978. Mind and society: The development of higher psychological processes. Cambridge, MA: Harvard University Press.

Wood, P., Bruner, J., \& Ross, G. 1976. The role of tutoring in problem solving. Journal of Child Psychology and Psychiatry, 17, 89-100.

(Manuscript received March 28, 2002; Revision accepted June 27, 2002) 